$\xi=-1$

\title{
Using Simulation for Development of The Systems of Automobile Gas Diesel Engine and its Operation Control
}

\author{
Mikhail G. Shatrov, Vladimir V. Sinyavski*, Andrey Yu. Dunin, Ivan G. Shishlov, \\ Andrey V. Vakulenko, Andrey L. Yakovenko
}

MADI, 64, Leningradsky Prosp., Moscow, 125319, Russia

*Corresponding author E-mail: sinvlad@mail.ru

\begin{abstract}
The work was aimed at the development of gas supply, diesel fuel supply and electronic control systems for automobile gas diesel engines. Different ways of diesel engine conversion to operate on natural gas were analyzed. Gas diesel process with minimized ignition portion of diesel fuel injected by the CR system was selected. Electronic engine control and modular gas feed systems which can be used on high- and middle-speed gas diesel engines were developed. Diesel CR fuel supply system was developed in cooperation with the industrial partner. Simulation was used to obtain basic parameters and control methods of these systems. The base diesel engine was converted into gas diesel engine using the systems developed. Bench tests of the gas diesel engine demonstrated a high share of diesel fuel substitution with gas, high fuel efficiency and large decrease of $\mathrm{NO}_{\mathrm{x}}$ and $\mathrm{CO}_{2}$ emissions.
\end{abstract}

Keywords: gas diesel engine; dual fuel engine; engine control system; gas feed system; diesel fuel system; injection rate shaping.

\section{Introduction}

Conversion of diesel engines into gas and gas diesel engines (dual fuel engines) provides many benefits and it is widely used today for automobile, locomotive, stationary and marine engines.

The reserves of gas on our planet are much higher than that of oil. Natural gas is cheaper than oil and the price difference will grow as more oil is produced from hard-to-reach deposits. According to forecasts, by 2035 , the amount of extracted natural gas will reach 5.1 billion tons and its proportion in fuel balance on Earth will grow up to $25 \%$ [1]. Engines fuelled with natural gas have much cleaner exhaust emissions compared with diesel, especially particles and nitrogen oxides. Change-over to natural gas makes it possible to decrease emission of $\mathrm{CO}_{2}$ up to $30 \%$ due to lower content of carbon in natural gas and its lower consumption compared with diesel fuel because of higher caloric effect of natural gas (methane).

The most efficient way of development of gas and gas diesel engines is conversion of existing diesel engines for operation on natural gas.

There are several methods of conversion of diesel engines to be fed with natural gas.

Spark ignition gas engines using a stoichiometric gas-air mixture Stable combustion of gas is ensured and three-way catalyst similar to that mounted on petrol engines may be used [2]. Stoichiometric gas-air mixture degrades fuel economy relative to diesel engine, but as natural gas is practically two times cheaper than diesel fuel in Russia, expenses for fuel decrease. Research of fuel consumption by buses in Serbia showed that buses with stoichiometric gas engines had by $10-25 \%$ higher fuel consumption than buses with diesel engines. Still as in Serbia, natural gas is by $52 \%$ cheaper than diesel fuel, expenses for gas fuel are significantly lower [3] Stoichiometric gas engines have pretty high exhaust gas tempera- ture which may result in deterioration of the turbocharger and this is an obstacle for high boosting.

Spark ignition gas engines using a lean gas-air mixture have a low exhaust gas temperature and therefore may be boosted much higher. They also have high fuel efficiency and low emissions of $\mathrm{NO}_{x}$ which enables to eliminate a reduction catalyzer for complying with ecological standards. Prechamber with enriched gas-air mixture is often used for middle-speed gas engines to inflame and control the lean mixture combustion in the main combustion chamber. The FEV company developed a prechamber system for a gas engine operating on a lean gas-air mixture. To get the efficient combustion without knock and low $\mathrm{NO}_{\mathrm{x}}$ emissions, the prechamber dimensions, as well as the number and size of the prechamner holes, their orientation were optimized. The Miller cycle was used. Simulation was made using the Charge Motion Design (CMD) package to investigate the influence of turbulence on the combustion process. Experiments were carried out on a one-cylinder diesel engine converted for operation on natural gas. After thorough calculation and experimental perfection, a very high mean indicated pressure 32 bars was attained, there was no knock and emissions of $\mathrm{NO}_{\mathrm{x}}$ did not exceed the limits of the standard TA-Luft [4]. Jenbacher J624 (type 6) engines working on lean gas-air mixture having $\mathrm{D} / \mathrm{S}=190 / 210 \mathrm{~mm}$ operating at $1500 \mathrm{rpm}$ are used for power generation. They have a gas enriched prechamber and attain a high brake mean effective pressure $2.4 \mathrm{MPa}$. The advanced Miller cycle is used there to avoid knock, raise the thermal efficiency up to $48.7 \%$ and reduce emissions of $\mathrm{NO}_{\mathrm{x}}$. The two-stage turbocharging system is mounted to compensate for filling efficiency degradation caused by the Miller cycle [5, 6]. This is a perfect solution for power generation because the engine operates constantly at a high speed which prevents knock. Worse fuel efficiency against gas diesel engines is compensated by lower gas price when the engine is connected directly to the gas pipe. In Russia, gas directly from the pipe may be up to four times cheaper than at the filling 
station [2]. The use of spark ignition lean mixture combustion on high boosted transport engines is limited by knock which appears at low speeds and transfer modes especially in engines having large cylinder size.

Gas diesel (dual-fuel) engines may have larger cylinder size and higher boosting as they do not have a problem of knock. Gas diesel engines with a mechanical diesel fuel supply system have a comparatively low substitution of diesel fuel with gas. The percentage of diesel fuel is $20-30 \%$ at full loads, it grows when the load decreases and reaches $100 \%$ at idle [7]. The percentage of diesel fuel may be decreased and many engine parameters significantly improved if the Common Rail (CR) system is used which injects a small portion of diesel fuel to ignite the gas-air mixture.

The analyses conducted in the Nikolai Bauman Moscow State Technical University [8] demonstrated that if the fuel sprays are larger, ignition stability of the gas is higher and the ignition portion of diesel fuel may be lower. If the injector nozzle holes do not change, the fuel spray size depends mainly on the diesel fuel injection pressure (if the pressure grows, the fuel drops become smaller and the fuel spray surface increases), speed and direction of the working medium movement during the compression stroke (if the speed increases, the mixture formation and combustion of the gasair mixture improve), backpressure in the cylinder (if the backpressure increases, the diesel fuel atomization improves). At low engine speeds and loads, the pressure and speed of the working medium in the cylinder decrease, also the backpressure drops due to lower boost pressure. Therefore a very small diesel fuel ignition portion that can be less than 5\% at high load has to be augmented at low loads. One can obtain larger fuel sprays by raising the injection pressure and using a special baffled piston to increase the tangential speed of the working medium.

The problems of combustion in gas diesel engines are reviewed in [9]: high percentage of $\mathrm{HC}$ and $\mathrm{CO}$ emissions caused by incomplete combustion in some areas especially at low loads, cycle to cycle instability at high loads. To solve these problems, a number of parameters should be thoroughly controlled: pilot dose of diesel fuel and its multistage injection, diesel fuel injection timing, the amount of gas, the amount and temperature of air entering the cylinder taking into consideration engine speed and load. Using a fast and efficient control algorithm is the best way to solve these problems. A simple 0-dimensional combustion model for gas diesel engine was developed for engine control. It uses Vibe formula for diesel fuel combustion, calculates heat exchange with the walls and thermodynamic parameters of the working medium. Combustion of the natural gas is calculated on the base of one-step macro reactions of the mixture main components. After the model was validated using the tests results of a four-cylinder 2.636 liter gas diesel engine, it showed a high agreement of calculated and experimental parameters.

Based on the analysis fulfilled, gas diesel cycle using a minimized portion of diesel fuel supplied by the CR system was chosen for automobile engine because it ensures high boosting, engine efficiency, ecological parameters and avoids knock.

\section{Computer modelling}

A pretty simple and fast 0 -dimensional model was used for calculation of gas diesel engine parameters [10]. The model uses Vibe formula for heat release and Woschni formula for heat losses calculation, empirical formulas for determining cylinder walls temperature and mechanical losses. It takes into account composition of the working medium at any time of the engine cycle. Gas exchange is calculated based on the quasi-stationary method, compressor and turbine maps are utilized for calculation of parameters at the cylinder inlet and outlet. The model was used for the following aims:

- Calculations of the following basic parameters of the gas diesel engines were required for development and adjustment of the gas feed, diesel fuel supply and electronic engine control systems

- Injection rate of gas and diesel fuel

- Counterpressure in the cylinder at the time of diesel fuel injection start

- Optimal diesel fuel injection advance angle in wide range of engine speeds and loads

- Analysis of experimental parameters obtained during the engine tests of the gas diesel engine after the systems developed were manufactured, mounted on the engine and their final adjustment was made.

\section{Gas diesel engine systems developed}

Research was carried out for the Cummins KAMA in-line 6cylinder gas diesel engine having $\mathrm{D} / \mathrm{S}=107 / 124 \mathrm{~mm}$, compression ratio $17.3: 1$, break mean effective pressure $1.73 \mathrm{MPa}$ at rated speed $2300 \mathrm{rpm}$. For conversion of diesel engines into gas diesel engines, electronic engine control, modular gas feed and CR fuel supply systems were developed.

\subsection{Electronic engine control system}

A completely new electronic engine control system for 6-cylinder gas diesel engines was developed which controls supply of gaseous and diesel fuel (Fig. 1). The system generates electric control impulses to control actuators and carries out synchronization and distribution of impulses by the cylinders depending on the engine operation mode on the basis of information received from many sensors

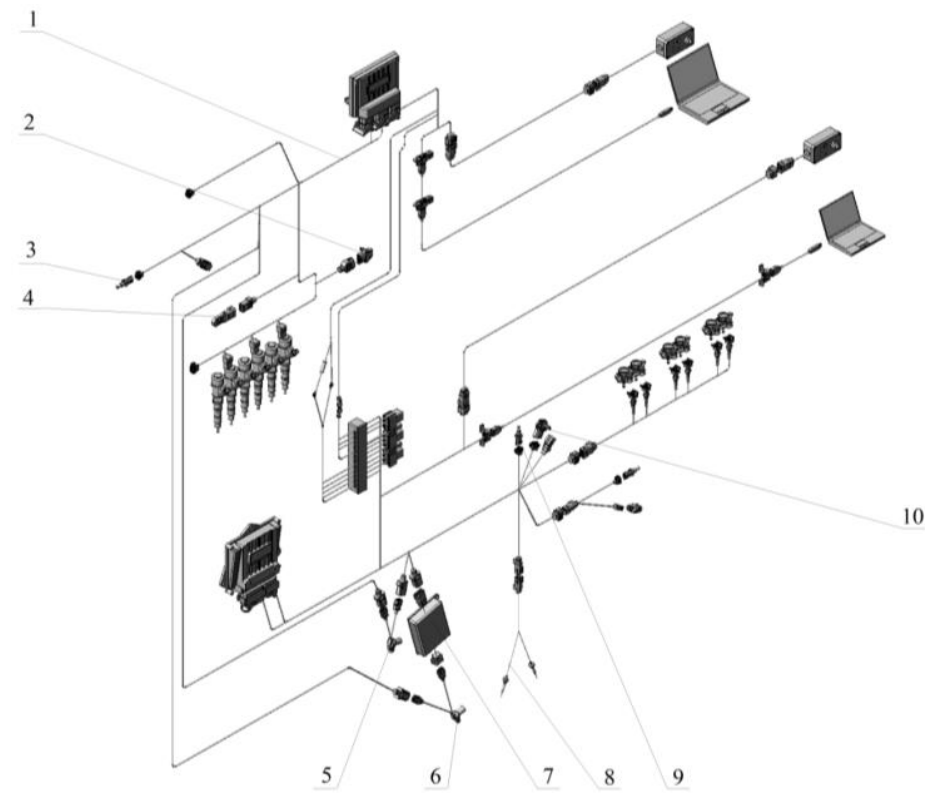

Fig. 1: Components of electronic engine control system for the gas diesel engine: 1 - information-calculation block; 2, 10 - intake manifold temperature and pressure sensors; 3, 9 - cooling agent temperature sensors; 4 - barometric correction sensor; 5 - crankshaft position sensor; 6 camshaft position sensor; 7 - crankshaft and camshaft position sensors adapter; 8 - block of thermocouples

\subsection{Modular gas feed system}

The gas feed system [11] has a modular design which enables to use it on engines having different size. Each module ensures reduction of pressure and supply of natural gas. One module is used on the automobile Cummins KAMA gas diesel engine and three modules, for example, on the middle-speed locomotive D200 six cylinder gas diesel engine having $\mathrm{D} / \mathrm{S}=200 / 280 \mathrm{~mm}$. 


\subsection{Common Rail fuel system for supply of the ignition portion of diesel fuel}

In the course of applied research and experimental development, a domestic Common Rail fuel supply system for a truck diesel engine was developed (Fig. 2).

Domestic manufacturers of diesel engines KAMAZ Public Company, MMZ Open Company, Avtodiesel (YaMZ) Public Company aimed at the development of engines with perspective energetic and ecological parameters may become potential customers of the additional variant of fuel supply system being developed for other models of diesel engines. In this connection, important tasks are ensuring injection pressure up to $200 \mathrm{MPa}$ and higher [12], as well as injection rate front shape control $[13,14]$ and organization of traditional fuel distribution in the combustion chamber [15].

The low pressure line of the fuel supply system includes (Fig. 3): fuel feed pump 1, fuel filter 2, connecting tubes 3 .

The high pressure line includes: high pressure fuel pump (HP pump) 4 , coupler 6.1 , common rail 6.2 , CR injectors 9 , fuel lines
5.1. The pressure sensor 7 and emergency valve 8 are mounted on the coupler.

The HP pump 4, fuel lines 5 and CR injectors 9 ensure fuel injection into diesel engine cylinder with pressure 30 ... $200 \mathrm{MPa}$. Fuel consumed for injector control enters a common low pressure line (not shown in Fig. 2) from each CR injector.

The fuel from each of four sections of the HP pump 4 enters the coupler 6.1 which is equipped with the fuel pressure sensor 7 and emergency valve 8 via the fuel lines 5.1.

The coupler 6.1 is connected with the common rail 6.2 which supplies the CR injectors 9 with fuel.

The HP fuel pump has a traditional design (Fig. 3): in-line with closed case 1 (without hatch) and insert sections with bodies 4 . The camshaft 7 - with cams in the shape of eccentrics. The delivery valve 11 has a traditional design with relief collar. Variation of the injection rate of the HP fuel pump is effected by the control valve 14 .

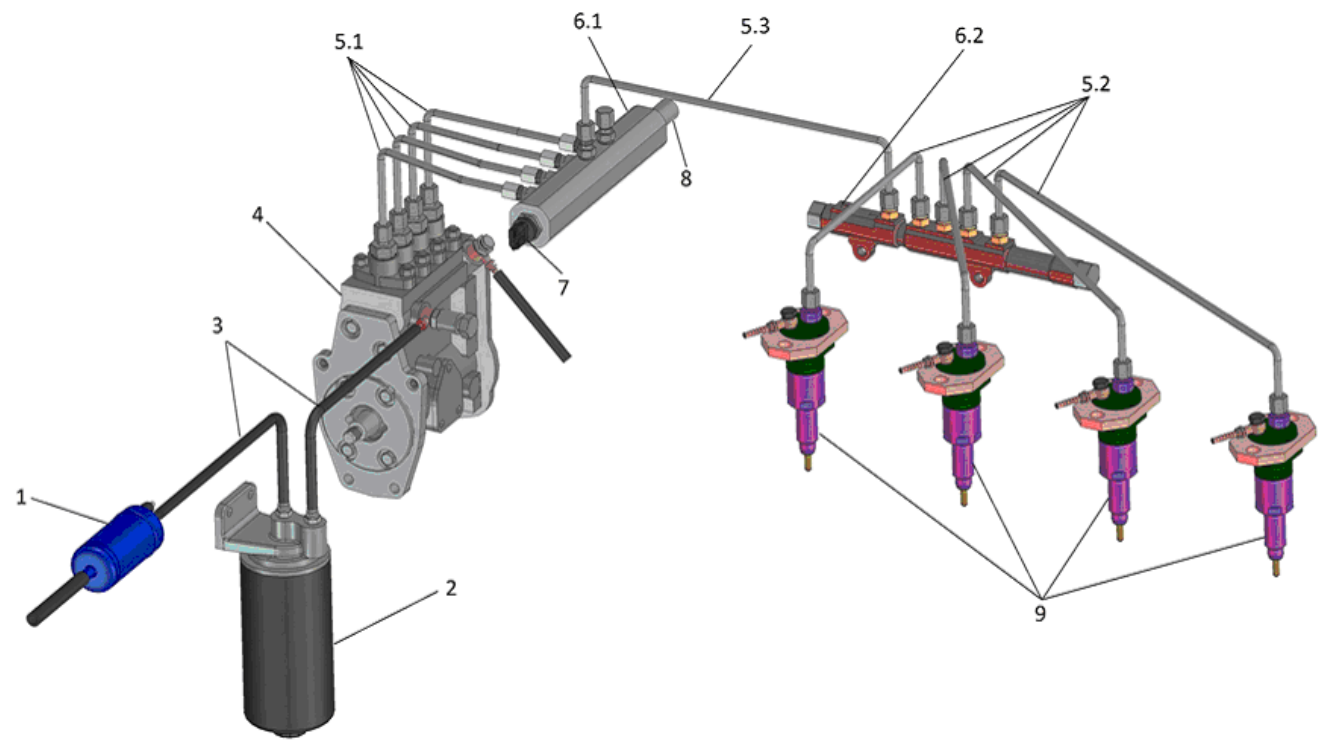

Fig. 2: Common Rail fuel supply system for a truck diesel engine:

1 - fuel feed pump; 2 - filter; 3 - low pressure fuel lines; 4 - high pressure fuel pump; 5.1, 5.2 and 5.3 - high pressure fuel lines; 6.1 - coupler; 6.2 common rail; 7 - pressure sensor; 8 - emergency valve; 9 - CR injector
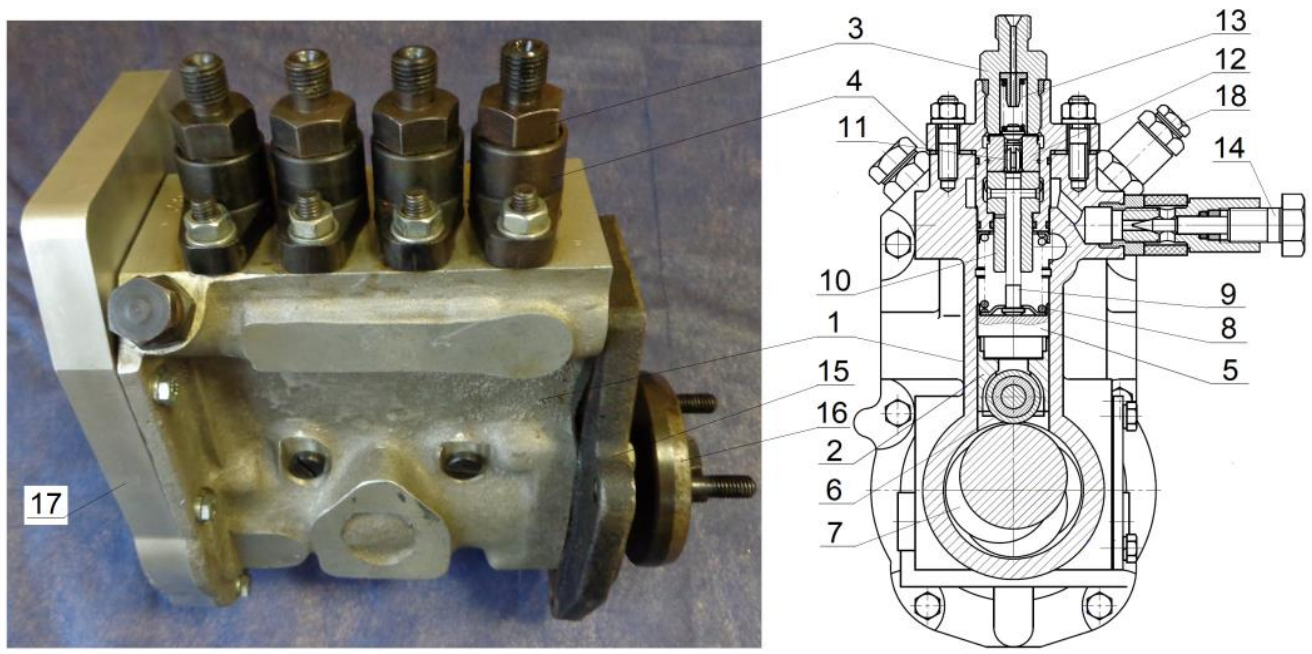

Fig. 3: HP fuel pump:

1 - HP fuel pump body; 2 - tappet; 3 - push fitting; 4 - insert section body; 5 - plunger support; 6 - tappet roller; 7 - camshaft; 8 - plunger spring; 9 plunger; 10 - plunger liner; 11 - delivery valve; 12 - delivery valve seat; 13 - delivery valve spring; 14 - control valve; 15 - plate fastening the HP fue pump to the engine; 16 - HP fuel pump drive flange; 17 - HP fuel pump rear cover; 18 - bypass valve

In Fig. 4, a scheme of the CR injector (CRI) and four laboratory prototypes are presented. 

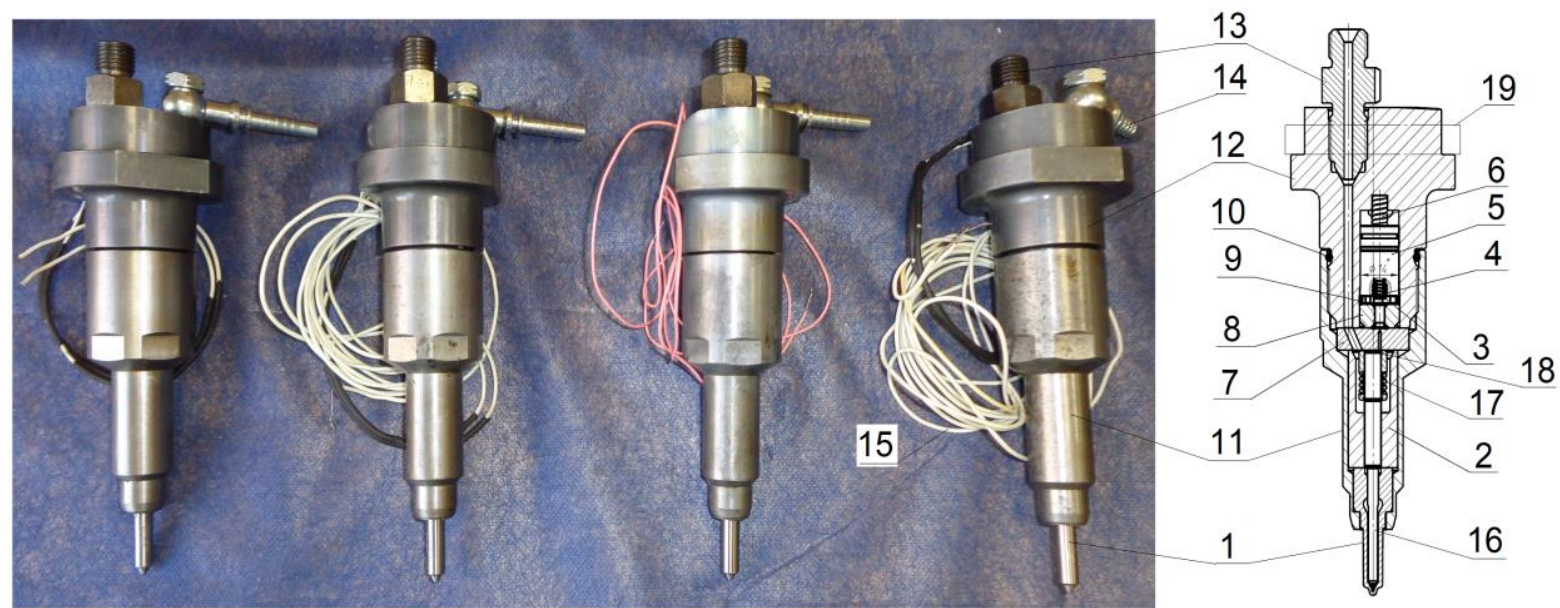

Fig. 4: CR injectors:

1 - injection nozzle; 2 - spacer; 3 - armature; 4 - armature spring; 5 - electromagnet; 6 - magnet spring; 7 - valve seat; 8 - armature body; 9 - spacer; 10 - ring; 11 - nozzle nut; 12 - injector body; 13,14 - connectors; 15 - electromagnet power wires; 16 - needle valve; 17 - needle valve spring; 18 - control chamber; 19 - clamp mounting point

The use of the "floating bush" in the design may be considered as a modern approach enabling to increase the service life of the CRI.

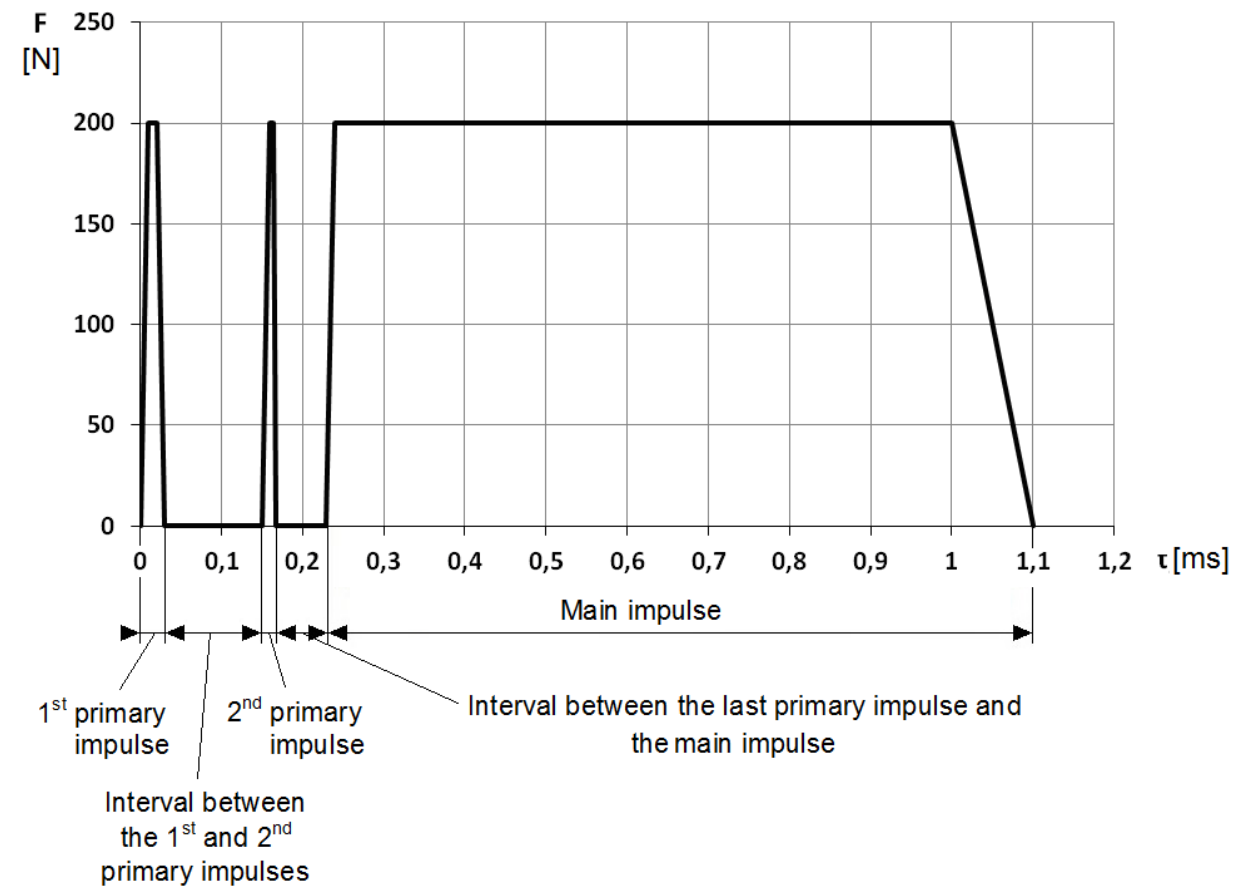

Fig. 5: The force of an electric magnet formed by two primary and one basic control impulses

\section{Results and discussions}

\subsection{Results of diesel fuel supply system simulation}

The desired fuel injection law at any operation mode of the engine is formed by variation of the control impulse duration [13, 14] and pressure in the common rail 6.2. (Fig. 2). It also depends on wave phenomenon originating in the high pressure line and having a considerable impact on the fuel injection process in case of a multistage injection [16].
To estimate the potential of injection rate control using this method, a series of calculations was carried out using the program complex developed in MADI (Fig. 5 ... 7).

The reviewed method of injection rate shaping is applicable in cases when the control impulse consists of:

- $\quad$ Primary and main impulses (Fig. 8 and 9),

- Main and additional impulses, following the main impulse (Fig. 10),

- $\quad$ Primary, main and post impulses (Fig. 11). 


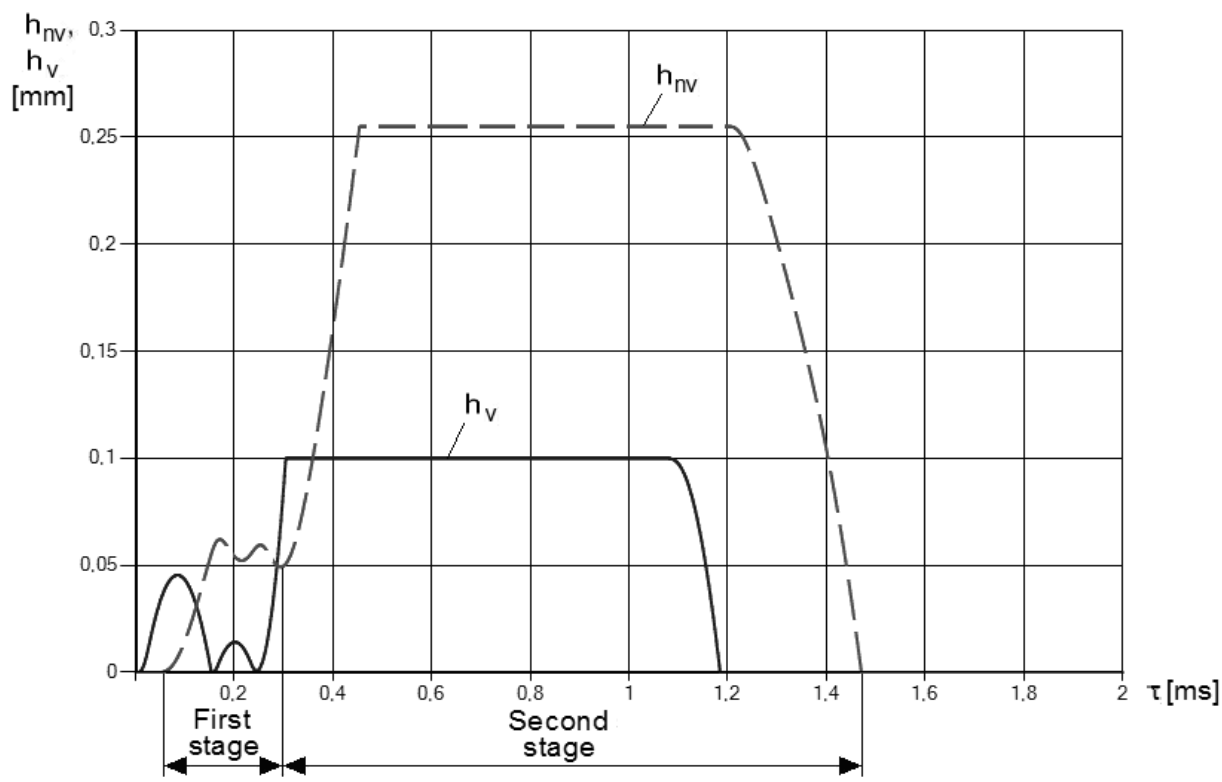

Fig. 6: Results of calculation of the displacement of the needle valve $h_{n v}$ and control valve $h_{v}$

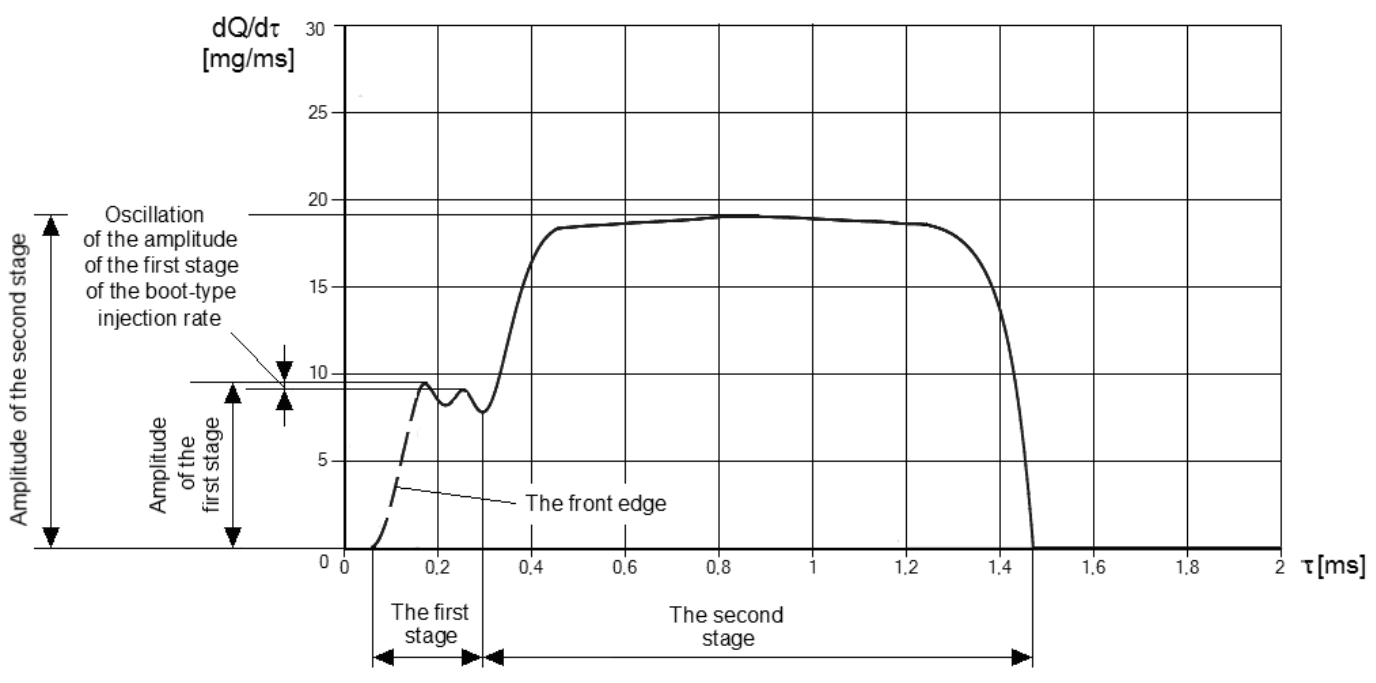

Fig. 7: Calculated boot-type injection rate shape formed by two primary and one main control impulses
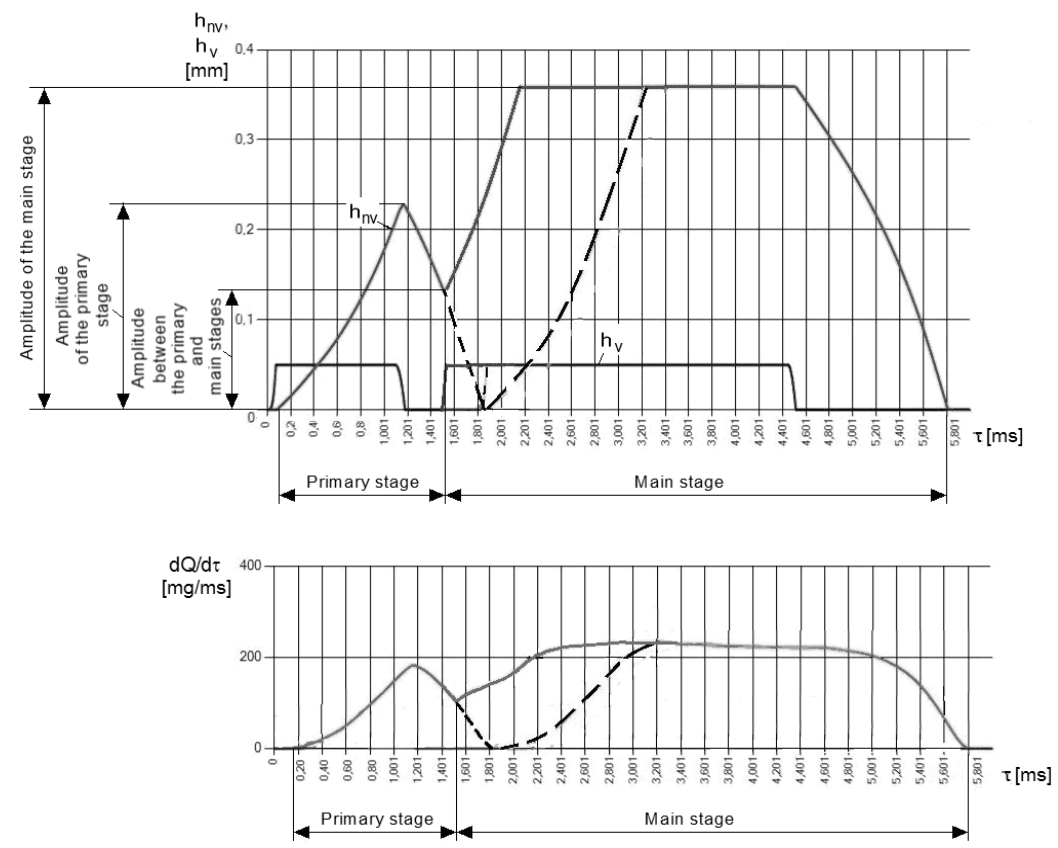
Fig. 8: Results of computer modeling of the influence of the time of the main electric impulse start on the control valve lift $h_{v}$, needle valve lift $h_{n v}$ of the Common Rail injector and on the injector rate shaping
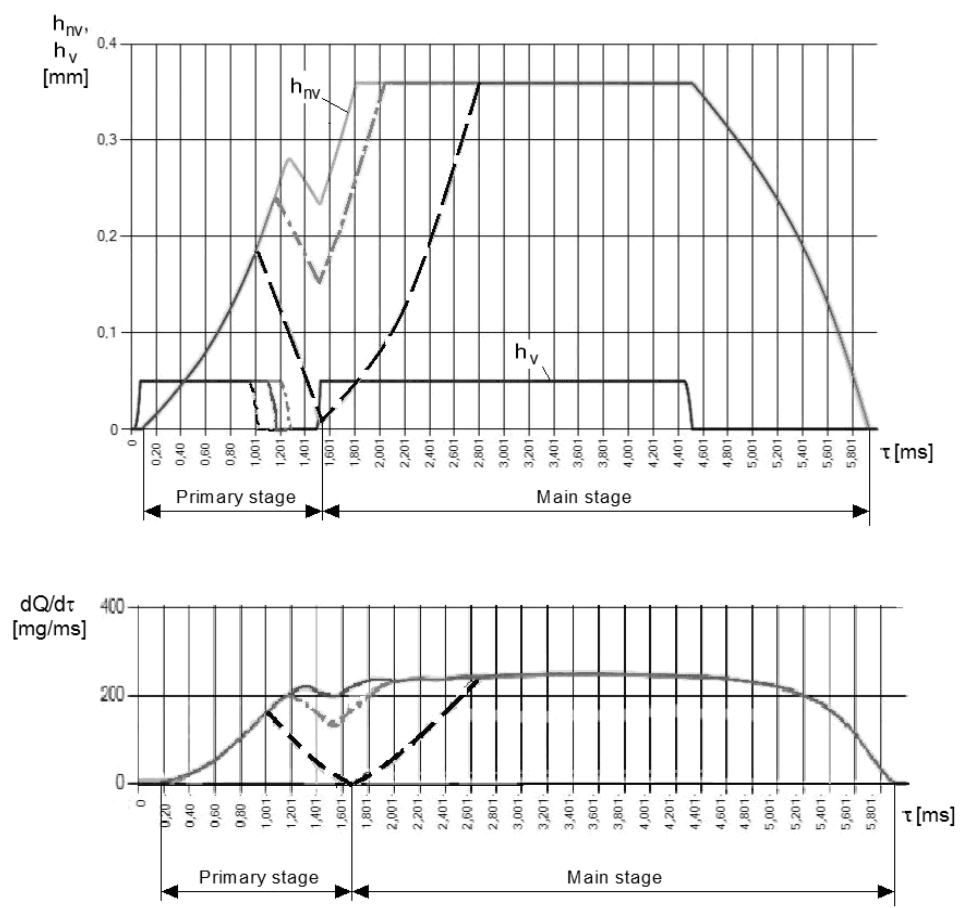

Fig. 9: Results of computer modeling of the influence of variation of the duration of the primary electric impulse on the control valve lift $h_{v}$, needle valve lift $\mathrm{h}_{\mathrm{nv}}$ of the Common Rail injector and on the injection rate shaping
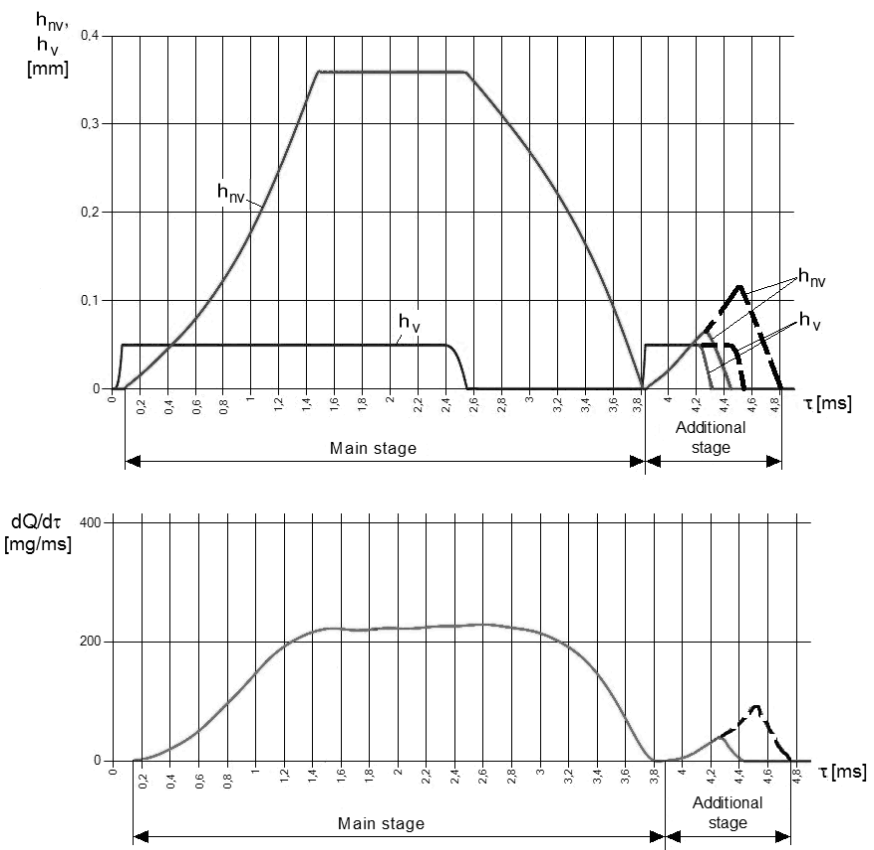

Fig. 10: Results of computer modeling of the influence of the variation of duration of the additional electric impulse on the control valve lift $h_{v}$, needle valve lift $\mathrm{h}_{\mathrm{nv}}$ of the Common Rail injector and on the injection rate shaping
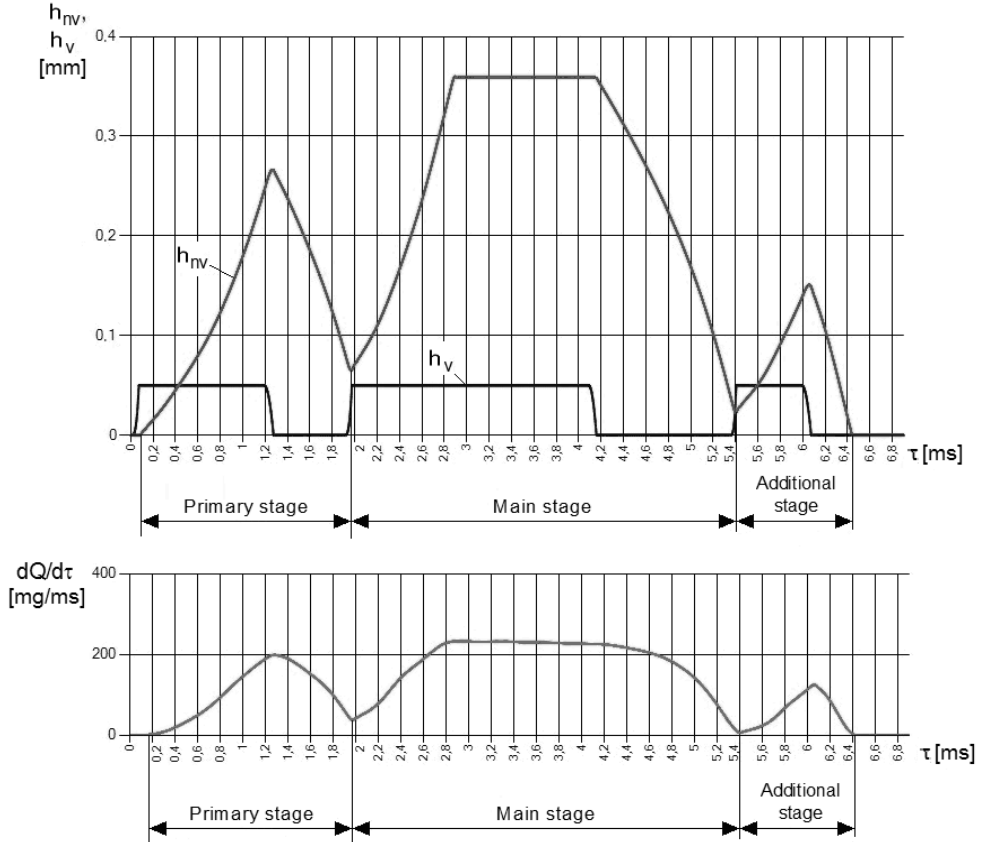

Fig. 11: Results of computer modeling of the control valve lift $h_{v}$, needle valve lift $h_{n v}$ and the injection rate shaping when applying a primary, main and following it additional electric impulses

\subsection{Results of engine bed tests}

The results of the Cummins KAMA gas diesel engine tests by the load and full-load characteristics are presented in Fig. 12 and Fig. 13 .

To check the accuracy of the computer model and analyse the experimental results, parameters of the engine at all operation modes were calculated and compared with the experimental data. During calculations, experimental values of gas consumption $G_{g}$ and diesel fuel consumption $G_{d}$ were used. 


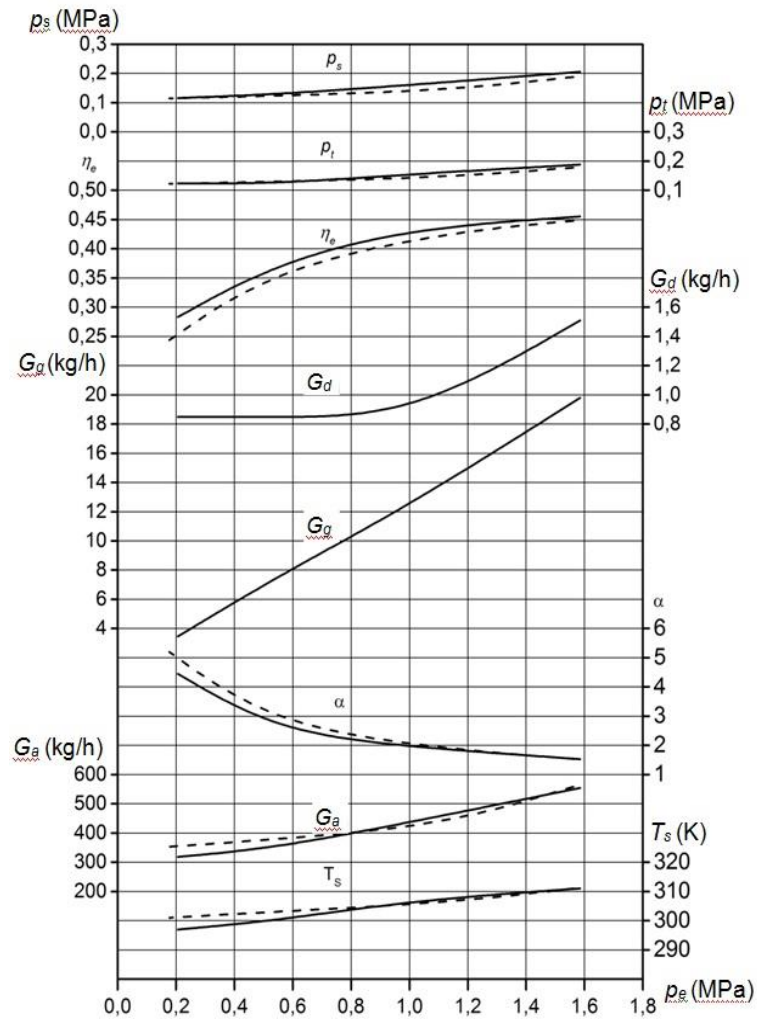

Fig. 12: Load characteristic of the gas diesel engine at $n=1420 \mathrm{rpm}$ : - calculation; - - experiment

Fig. 12 and 13 show a high effective efficiency $\eta_{e}=0.43-0.45$ at full speed and load of the engine. The calculated and experimental values of the boost pressure $p_{s}$, gas pressure before the turbine $p_{t}$ air consumption $G_{a}$, air access coefficient $\alpha$, boost air temperature $T_{s}$ and effective efficiency $\eta_{e}$ at high load and high engine speed are close. The difference between parameters $G a, \alpha$ and $\eta_{e}$ is larger at low loads (Fig. 12) which may be explained by not very accurate description of experimental compressor and turbine maps by polynomials at low engine loads.

As seen from Fig. 13, the values of mean effective pressure $p_{e}$ are pretty low at low engine speeds. This may be caused by decrease of the amount of air in the cylinder and as a consequence - of the air access coefficient $\alpha$ because the air is partially substituted by gas compared with the base diesel engine. The airflow in the gas diesel engine was almost by $8 \%$ lower than in the base diesel engine.

Other reasons may be similar to those described in [8]. In diesel engine, all the fuel is located in the combustion chamber. In gas diesel engine, a part of gas fills the gaps between piston/cylinder head and piston/liner where it burns incompletely or does not burn at all. This effect is stronger at low engine speed when the air turbulence in the cylinder is low. This phenomenon is indirectly confirmed by a higher calculated effective efficiency $\eta_{e}$ compared with its experimental value at low engine speed (Fig. 13) because incomplete combustion of fuel in the gaps is not taken into consideration in the simulation model implemented.

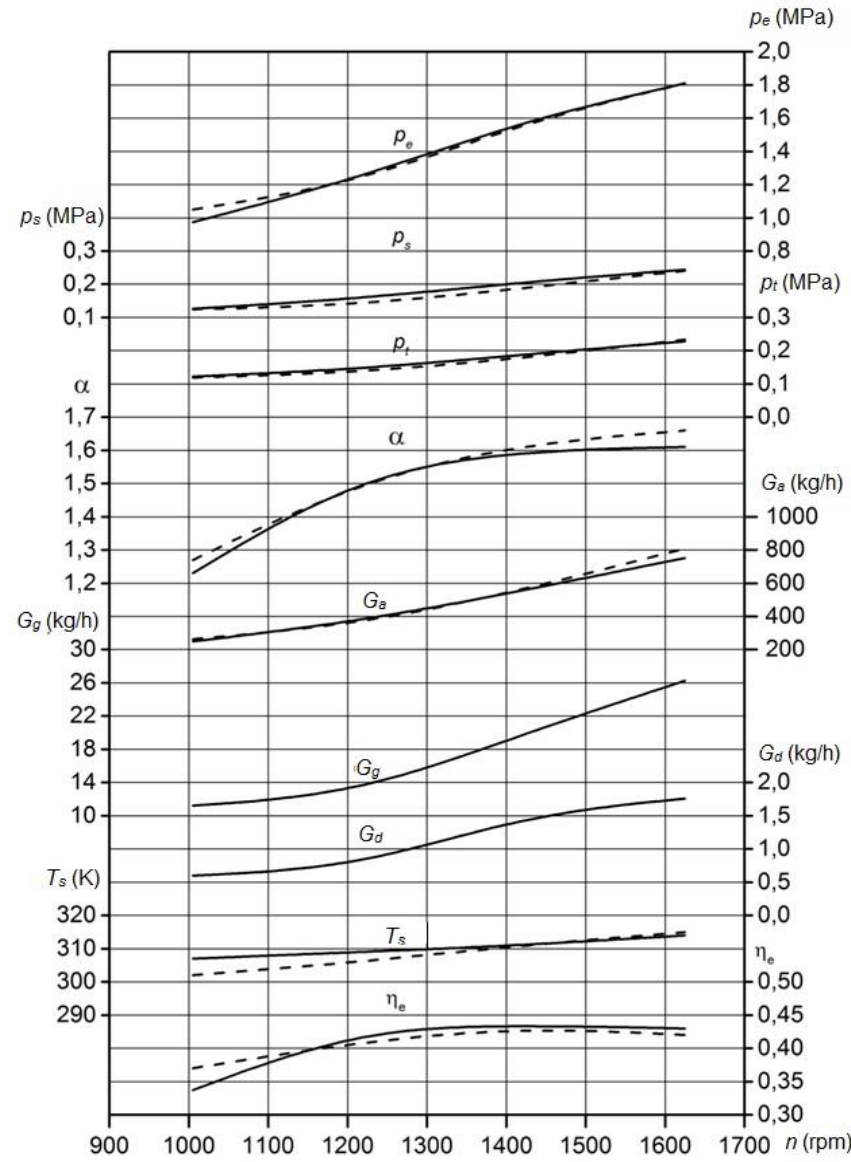

Fig. 13: Full-load characteristic of the gas diesel engine:

- calculation; - - experiment

Tuning of the turbocharger may result in some increase of the mean effective pressure at low engine speeds. But to get the high values of $p_{e}$ as in the base diesel engine, the shape of the combustion chamber should be redesigned

The comparison of parameters of the base Cummins KAMA diesel engine and its gas diesel version at three engine speeds and two loads: maximal and partial (30-40\%) was carried out in [17]. At full loads, the percentage of diesel fuel was $4.5-6.2 \%$, at low loads $-8.7-8.9 \%$. The percentage of diesel fuel at idle was 33\%. The effective efficiency of the gas diesel engine was approximately by $2 \%$ higher than of the base diesel engine and its highest value was 0.45 . On the average, at full and partial loads, correspondingly, emissions of $\mathrm{CO}_{2}$ decreased 1.47 and 1.15 times and amounted to $7.6 \%$ and $3.3 \%$ while emissions of $\mathrm{NO}_{\mathrm{x}}$ decreased 7.4 and 1.52 times and amounted to $1007 \mathrm{ppm}$ and $140 \mathrm{ppm}$.

\section{Conclusion}

1. The analysis demonstrated that gas diesel working process with a minimized igniting portion of diesel fuel supplied by the CR system is the most reasonable way of conversion of automobile diesel engine for operation on natural gas.

2. Calculations of gas diesel engine at different modes were carried out to get parameters required for the development and adjustment of gas feed, diesel fuel supply and engine electronic control systems. The base high-speed diesel engine was converted into gas diesel engine and used for experimental perfection of these systems.

3. After conversion of the base diesel engine into gas diesel engine using the systems developed, a high degree of diesel fuel substitution by gas was achieved: the average diesel fuel portion amounted to 5.6, 8.8 and $33 \%$, correspondingly, at full load, ap- 
proximately $35 \%$ load and idle. On the average, emissions of $\mathrm{CO}_{2}$ decreased 1.47 and 1.15 times and emissions of $\mathrm{NO}_{\mathrm{x}}$ decreased 7.4 and 1.52 times correspondingly, at full and partial loads. Effective efficiency of the gas diesel was on the average by 2 percent higher than of the base diesel engine and its maximal value was 0.45 .

\section{Acknowledgement}

Applied research and experimental development of diesel fuel feed systems are carried out with financial support of the state represented by the Ministry of Education and Science of the Russian Federation under the Agreement No 14.580.21.0002 of 27.07.2015, the Unique Identifier PNIER: RFMEFI58015X0002.

\section{References}

[1] Markov VA, Gaivoronski AI, Grehov LV \& Ivaschenko NA (2008), Operation of Diesel Engine on Non-Traditional Fuels. LegionAvtodata, Moscow, $464 \mathrm{p}$.

[2] Luksho VA, A Complex Method of Increasing Energy Efficiency of Gas Engines with High Compression Ratio and Shortened Intake and Exhaust Strokes, Ph.D. Thesis, NAMI, Moscow, 2015, 365 p.

[3] Ivković IS, Kaplanović SM \& Milovanović BM (2017), Influence of Road and Traffic Conditions on Fuel Consumption and Fuel Cost for Different Bus Technologies. Thermal Science, 21(1B), 693-706.

[4] Geiger J, Heuser P, Lauer S, Huchtebrock B \& Sankhla H (2013), Combustion System Development for a Large Bore Gas Engine Efficient Combination of Simulation and Experiment. Paper no 80, $27^{\text {th }}$ SIMAC Congress, Helsinki.

[5] Klausner J, Lang J \& Trapp C (2011), J624 - Der weltweit erste Gasmotor mit zweistufiger Aufladung, MTZ - Motortechnische Zeitschrift Ausgabe, Vol. 04.

[6] Grotz M, Böwing R, Lang J, Thalhauser J, Christiner P \& Wimmer A (2015), Efficiency Increase of a High Performance Gas Engine for Distributed Power Generation, 6th CIMAC Cascades. Dual Fuel and Gas Engines - Their Impact on Application, Design and Components.

[7] Kudryavtzev A \& Lomashov V (2010), Belaz Trucks of XXI Century with DM Family Gas Diesel Engines. AvtoGasoZapravochniy komplex + Alternatvnoye toplivo/AutoGasFillingComplex + Alter native Fuel, 3, 3-6.

[8] Grehov LV, Ivaschenko NA \& Markov VA (2010), On Ways to Improve the Gas Diesel Cycle. AvtoGasoZapravochniy komplex + Alternatvnoye toplivo/AutoGasFillingComplex + Alternative Fuel, 7(100), 10-14.

[9] Mikulski M \& Wierzbicki S (2017), Validation of a ZeroDimensional and Two-Phase Combustion Model for Dual-Fuel Compression Ignition Engine Simulation. Thermal Science, 21(1B), 387-399.

[10] Khatchijan AS, Sinyavskiy VV, Shishlov IG \& Karpov DM (2010), Modeling of Parameters and Characteristics of Natural Gas Powered Engines. Transport na Alternativnom Toplive/Transport on Alternative Fuel, 3(15), 14-19.

[11] Shatrov MG, Sinyavski VV, Dunin AY, Shishlov IG \& Vakulenko AV (2017), Method of conversion of high- and middle-speed diesel engines into gas diesel engines. Facta Universitatis. Series: Mechanical Engineering, Vol. 15, No 3, 383-395.

[12] Shatrov MG, Golubkov LN, Dunin AY, Yakovenko AL \& Dushkin PV (2015), Influence of high injection pressure on fuel injection performances and diesel engine working process. Thermal Science, Vol. 19, No. 6, 2245-2253.

[13] Shatrov MG, Golubkov LN, Dunin AY, Dushkin PV \& Yakovenko AL (2017), A method of control of injection rate shape by acting upon electromagnetic control valve of common rail injector. International Journal of Mechanical Engineering and Technology, Vol. 8, Issue 11, 676-690.

[14] Shatrov MG, Golubkov LN, Dunin AY, Dushkin PV \& Yakovenko AL (2017), The new generation of common rail fuel injection system for Russian locomotive diesel engines. Pollution Research, Vol. 36 (3), 678-684.

[15] Shatrov MG, Malchuk VI, Dunin AY \& Yakovenko AL (2016) The influence of location of input edges of injection holes on hydraulic characteristics of injector the diesel fuel system. International Journal of Applied Engineering Research, Vol. 11, No. 20, 10267-10273.
[16] Shatrov MG, Golubkov LN, Dunin AY, Yakovenko AL \& Dushkin P.V (2016), Experimental research of hydrodynamic effects in common rail fuel system in case of multiple injection. International Journal of Applied Engineering Research, Vol. 11, No. 10, 6949 6953.

[17] Sinyavski VV, Alekseev IV, Ivanov IY, Bogdanov SN \& Trofimenko YV (2017), Physical simulation of high- and mediumspeed engines powered by natural gas. Pollution Research, Vol. 36 (3), 684-690. 